\title{
Computerized Prompts for Cancer Screening in a Community Health Center
}

\author{
Kimberly S. H. Yarnall, MD, Barbara K. Rimer, DrPH, Denise Hynes, PbD, \\ George Watson, Pauline R. Lyna, MPH, C. T. Woods-Powell, MA, Jennifer Terrenoire, \\ and L. Thomas Barber, MD
}

Background: We describe the implementation and subsequent use of a computerized health maintenance tracking system in a large, urban, North Carolina community health center (Lincoln Community Health Center) as part of a larger study designed to increase rates of mammography, Papanicolaou tests, and smoking cessation in low-income African-Americans.

Methods: Clinicians from the Lincoln Community Health Center were involved in the design and implementation of the computer system. At each office visit, clinicians received a computerized encounter form indicating needed screening tests, counseling, and immunizations for each randomly selected study patient $(n=1318)$.

Results: Initial clinician compliance rates with filling out the form were 95 percent (mammography), 82 percent (Papanicolaou test), 77 percent (clinician breast examination), and 55 percent (smoking cessation). Cumulative compliance leveled off at 21 months to 65 percent, 57 percent, 53 percent, and 38 percent, respectively, despite multiple reminder strategies. When surveyed, most clinicians thought it was a good reminder system but said they did not always complete the form because of time demands. Costs of adapting and implementing the system were $\$ 23,332.08$ (\$17.70 per study). Per-patient costs would have been reduced further if more patients had been included in the project.

Conclusions: State-of-the-art computer prompting systems can be useful in a community health center; however, even with prompting, clinicians still only addressed health maintenance with their patients about 50 percent of the time. Additional interventions will be needed, particularly in low-income populations, to meet the Healthy People 2000 goals in health promotion. (J Am Board Fam Pract 1998;11:96-104.)

Not only do impoverished Americans suffer disproportionate burdens from cancer, but their overall cancer survival rate is 10 to 15 percent lower than the general population. ${ }^{1}$ The proportion of late-stage breast cancer increases with poverty level. ${ }^{2}$ One half of the difference in survival among poor people is attributed to late diagnosis; they might lack access to screening or do not get screened for other reasons. ${ }^{1,3-7}$ A similar picture emerges for cervical cancer screening. In

\footnotetext{
Submitted 8 July 1997.
}

From the Division of Family Practice, Department of Community and Family Medicine (KSHY), Duke Comprehensive Cancer Center (BKR, PUL, CTW-P, JT), and Biometry and Medical Information (GW), Duke University Medical Center, Durham, NC; the Department of Medicine, Lincoln Community Health Center (LTB), Durham, NC; and the Midwest Center for Health Services and Policy Research, Edward Hines, Jr, VA Hospital (DY), Hines, and Department of Medicine, Loyola University Chicago (DY), Maywood, Ill. Address reprint requests to Kimberly S. H. Yarnall, MD, Box 3886, Duke University Medical Center, Durham, NC 27710.

This research was supported by NIH Grant \# 5R01 CA59734-04, Enhancing Cancer Control In a Community Health Center. addition, poor Americans often are unaware of their increased risk for cancer or of their treatment options ${ }^{7}$ and might not know that detecting cancer in the early stages can increase their chance of survival. ${ }^{8,9}$ Factors that increase cancer risk, such as smoking, are more prevalent among persons living below the poverty level (32.1 versus 23.8 percent), and success in quitting is lower in that group than among persons at or above the poverty level ( 30.4 versus 52.4 percent). ${ }^{10}$

Community health centers have been vital in meeting the health needs of Americans who are below the poverty level or are working but underinsured or uninsured. ${ }^{11}$ A recent study of AfricanAmerican patients at community health centers in Chicago, however, found that most of the women were not having age-appropriate Papanicolaou tests and mammograms. ${ }^{12}$ Two factors influencing screening are whether the clinician counsels the patient to have the screening procedure and whether the patient follows the clinician's recommendation. Thus, it is important that clinicians 
discuss cancer risk and recommend cancer screening tests, such as clinical breast examinations, mammograms, and Papanicolaou tests. ${ }^{13,14} \mathrm{Clini}$ cians in community health care centers can have a major influence on both cancer prevention and early detection among their low-income clients.

Busy clinicians might forget to suggest cancer screening procedures or to inquire about patients' smoking status. ${ }^{15,16}$ A number of successful interventions, however, have been shown to increase clinicians' cancer prevention activities. ${ }^{7-19}$ Among these interventions are chart checklists, ${ }^{20-24}$ educational programs, ${ }^{21-25}$ and handwritten or computer-generated reminders attached to the patient's chart. ${ }^{25-34}$ Computerized prompts used to remind clinicians to promote cancer tests and smoking cessation were found to be effective in increasing the number of eligible patients who receive Papanicolaou tests, mammograms, and breast examinations. ${ }^{18,19,25,26,28,35-40}$

We conducted a study funded by the National Cancer Institute (NCI) to promote increased use of mammograms, Papanicolaou tests, and clinical breast examinations and to encourage smoking cessation among the patients of a North Carolina community health center. An integral part of the study was a clinician-directed intervention, a computer-generated form that had age- and patient-specific prompts to remind clinicians of cancer-related tests and counseling. The form was consistent with the $\mathrm{NCI}$-proved algorithmask, advise, assist, and arrange follow-up ${ }^{41}$-and has been used in other primary care settings. ${ }^{42}$

We discuss the design of the computer-generated form, its integration into the day-to-day functioning of the community health clinic, and the costs of implementing this computerized reminder system. We also report preliminary data on clinicians' compliance with the form and the barriers to using the prompting system.

\section{Methods}

\section{Patient Selection}

The Lincoln Community Health Center (Lincoln), a primary health care facility in Durham, NC, serves 30 percent of the African-American population of that city, and 85 percent of Lin- . coln's patients are African-American. The adult medicine division, where the study took place, has two clinics-Continuity Clinic and Walk-In (acute care).
A random sample of 3490 adult patients using the Lincoln Community Health Center was drawn from a list of all clients older than 18 years who had visited the center 18 months before November 1993. The sample was stratified by age and sex. Of the 3490 names in the original sample, 1071 (31 percent) were deleted because they represented disconnected or wrong numbers. Of the 2419 persons in the corrected sample, 22 percent could not be contacted after numerous attempts, 4 percent had hearing problems, and 3 percent refused to be initially interviewed. The final sample consisted of 1318 men and women, and they were randomly assigned to one of three intervention groups. Clinicians caring for the study patients received computer-generated prompts reminding them to inquire about smoking status and to discuss the appropriate breast or cervical cancer screening tests at the time of the patient visit. For patients in the first group, the computer-generated reminders were the only intervention.

Clinicians caring for patients in the second group also received computer-generated reminders; in addition, the patients received specially tailored, ethnically appropriate birthday cards and newsletters reminding them of the importance of cancer screening and smoking cessation, with additional information intended to help them overcome barriers to behavior change. Thus, the material was individualized to convey the information a particular patient would need.

For the third group, not only did the patients' physicians get computerized reminders on the encounter forms and the patients the tailored birthday cards, but the patients also received follow-up telephone calls from counselors who encouraged them to return for screening or to quit smoking. In the past, brief telephone calls have been shown to triple the odds that a woman would have a mammogram. ${ }^{43}$

Assessment of the impact of the patient-directed interventions and evaluation of the changes in patient knowledge and behaviors are still in progress. This report focuses on the implementation of the computer system and physician acceptance and use of the system.

\section{The Medical Record}

A computer system was created at Lincoln based on The Medical Record (TMR) computer system used at the Duke Family Medicine Center. TMR 
was developed at Duke University in the 1970s and has been used since the mid-1970s in the Duke Family Medicine Center. It is available commercially through Database, Inc. TMR is designed with multiple modules, each of which can be used as needed by a practice. The modules include programs to manage data for demographics and insurance, accounting, appointments, requests for ancillary studies and reporting of their results, pharmacy, problem lists, encounter or procedure notes, and a wide array of customizable reports. ${ }^{42}$

Because we had difficulty interfacing TMR with the Lincoln computerized billing system and because the vendor for programming changes for the Lincoln system had gone out of business, we designed a semimanual system that interfaced with medical records, nursing, and the clinicians. As a result, many of the tasks normally performed by computers at other TMR-supported practice sites, such as the automatic entry of radiology and laboratory test results, had to be entered into the Lincoln TMR manually so that Lincoln clinicians would have up-to-date test results and health maintenance prompts. For example, mammograms were ordered manually and entered into TMR. The paper with the order went with the patient to be entered into the community hospital computer, and the results of the mammogram were mailed back on paper to Lincoln and typed into TMR. This semimanual system resulted in higher costs than a completely automated system because of the need to pay a data technician to enter data into TMR. It met the needs of Lincoln, however.

\section{Development of Computerized Health Maintenance Prompts at Lincoln}

To adapt the standard TMR health maintenance prompts to the Lincoln Community Health Center needs, we met with the medical director (LTB) at Lincoln and reviewed its current paper health maintenance encounter form with physician representatives to determine which screening tests and counseling services were considered standards of care. We wanted to ensure that the computerized prompts would address a broad scope of health maintenance, thus improving the likelihood that the study clinicians would use the form.

The Lincoln clinicians chose the following pa- tient care recommendations and counseling reminders for the system: smoking status, Papanicolaou tests, mammograms, breast self-examination, clinical breast examination, cholesterol levels, rectal examination, assessment of activities of daily living, assessment of cardiovascular risk, and pneumococcus, diphtheria-tetanus, and influenza vaccinations. Because the standard TMR health maintenance prompts contained no patient education or physical examination prompts, new prompts were designed for smoking cessation counseling, breast self-examination counseling, clinical breast examination, rectal examination, cardiovascular risk assessment, and activities of daily living assessment.

The final Lincoln TMR health maintenance prompts (Figure 1) were printed on purple paper and attached to the chart of each study patient. The form contained patient demographics, a space for clinicians to record their provider identification number, and the name of the clinic in which they were seeing the patient, as well as ageand sex-specific prompts for tests or procedures for which the patient was eligible. These prompts included the Lincoln-recommended interval for the tests or procedures and the date that they were last performed, as well as the results for that patient, the next due date, and whether the patient was past due.

During the active study phase, clinicians noted on the form whether the past due items had been previously completed at an outside facility or whether they had been completed during the office visit. Clinicians also indicated the results of any physical examinations completed during the encounter. Using a coded data phrase, a numbered standard response, the Lincoln clinicians noted whether they performed a recommended test, such as a Papanicolaou smear, or ordered a test, such as a mammogram. In addition, the coded data phrases allowed the clinicians to indicate whether they had discussed the recommended test or procedure with the patient and whether they or the patient chose to delay the test until the next visit. Clinicians also could note whether the test was inappropriate for that visit or would never be appropriate for that patient (eg, a mammogram for a woman who had had a bilateral mastectomy). The TMR forms were collected at the end of each day and manually entered into TMR by a data technician. 
LCHC HEALTHY BIRTHDAYS PROJECT

Category: CONTINUITY

Primary MD:

Occupation:

Employer:

Date apt:

Printed: 09/23/96 16:41

WALK IN CLINIC CONTINUITY CLINIC REFERRED TO CONTINUITY CLINIC
PATIENT DEMOGRAPHICS

\begin{tabular}{l|l} 
RV & PATIENT DEMOGRAPHICS \\
JT & G. Smith \\
& Main Street \\
& Anytown, USA 27000-40 \\
& $919-999-9999$ \\
& Date of birth: $04 / 22 / 28$ \\
68 yo female
\end{tabular}

SPECIALTY CLINIC

PATIENT CARE RECOMMENDATIONS

\begin{tabular}{|c|c|c|c|c|c|}
\hline \multirow[t]{2}{*}{ TEST } & \multicolumn{2}{|c|}{ RECOMMENDED } & \multicolumn{2}{|c|}{ LAST DONE } & \multirow{2}{*}{$\begin{array}{c}\text { NEXT SCREENING } \\
\text { DATE }\end{array}$} \\
\hline & AGE & FREQUENCY & RESULT & DATE & \\
\hline SMOKING & AGE $18+$ YR & EVERY VISIT & ADVISED & $01 / 27 / 95$ & ${ }^{*}$ DUE NOW* \\
\hline CHOLESTEROL & AGE $18-70$ YR & EVERY 5 YR & 174 & $11 / 10 / 94$ & DUE $11 / 10 / 99$ \\
\hline DT & AGE 18+ YR & EVERY $10 \mathrm{YR}$ & DONE & $01 / 11 / 95$ & DUE $01 / 10 / 05$ \\
\hline PNEUMOCOCCA & AGE $65+$ YR & ONCE & DONE & $01 / 11 / 95$ & \\
\hline INFLUENZA & AGE $65+\mathrm{YR}$ & EVERY 1 YR & DONE & $11 / ? ? / 94$ & ${ }^{*}$ DUE NOW* \\
\hline RECTAL EXAM & AGE 40+ YR & EVERY 1 YR & UNRECORDED & $01 / 11 / 95$ & ${ }^{*}$ DUE NOW* \\
\hline ADL ASSESSM & AGE $65+\mathrm{YR}$ & EVERY 1 YR & & & ${ }^{*}$ DUE NOW* \\
\hline CVR RISK & AGE $18+$ YR & ONCE & DONE & $01 / 11 / 95$ & \\
\hline PAP & AGE $18+\mathrm{YR}$ & EVERY 1 YR & & & ${ }^{*}$ DUE NOW* \\
\hline MAMMOGRAM & AGE $50+$ YR & EVERY 2 YR & & & ${ }^{*}$ DUE NOW* \\
\hline BREAST SELF & AGE $18+$ YR & EVERY 1 YR & & & ${ }^{*}$ DUE NOW* \\
\hline BREAST MD & AGE $35+\mathrm{YR}$ & EVERY 1 YR & UNRECORDED & $12 / 06 / 94$ & ${ }^{*}$ DUE NOW* \\
\hline
\end{tabular}

\section{COUNSELING NEEDED THIS VISIT}

SMOKING

RX: NICOTINE PATCH

NICOTINE GUM

NEVER SMOKED:

PREVIOUS SMOKER: - . - - > IN PAST 2 YEARS

SMOKER - . - . > ASKED

ADVISED

2 OR MORE YEARS AGO ASSISTED PICKED DATE

\begin{tabular}{cccc}
\hline TEST PLACE & DATE & RESULT & ACTION CODE \\
& & (NORMAL/ABNORMAL/VALUE)
\end{tabular}

INFLUENZA

RECTAL EXAM

ADL ASSESSME

PAP

MAMMOGRAM

BREAST SELF

BREAST MD

ACTION CODES: I=DONE TODAY, 2=0RDERED, 3=DISCUSSED/PATIENT DELAYED, $4=$ =ISCUSSED/MD DELAYED, 5=NOT APPROPRIATE THIS VISIT, $6=$ =NEVER APPROPRIATE

$11 / 10 / 94$

PLACE

PRIMARY PROVIDER

CHOL $\quad 105-200$
WALK IN C

MISSING M

MG/DL 174

Figure 1. Lincoln Community Health Center health maintenance prompts attached to each study patient chart for The Medical Record (TMR) data collection. 


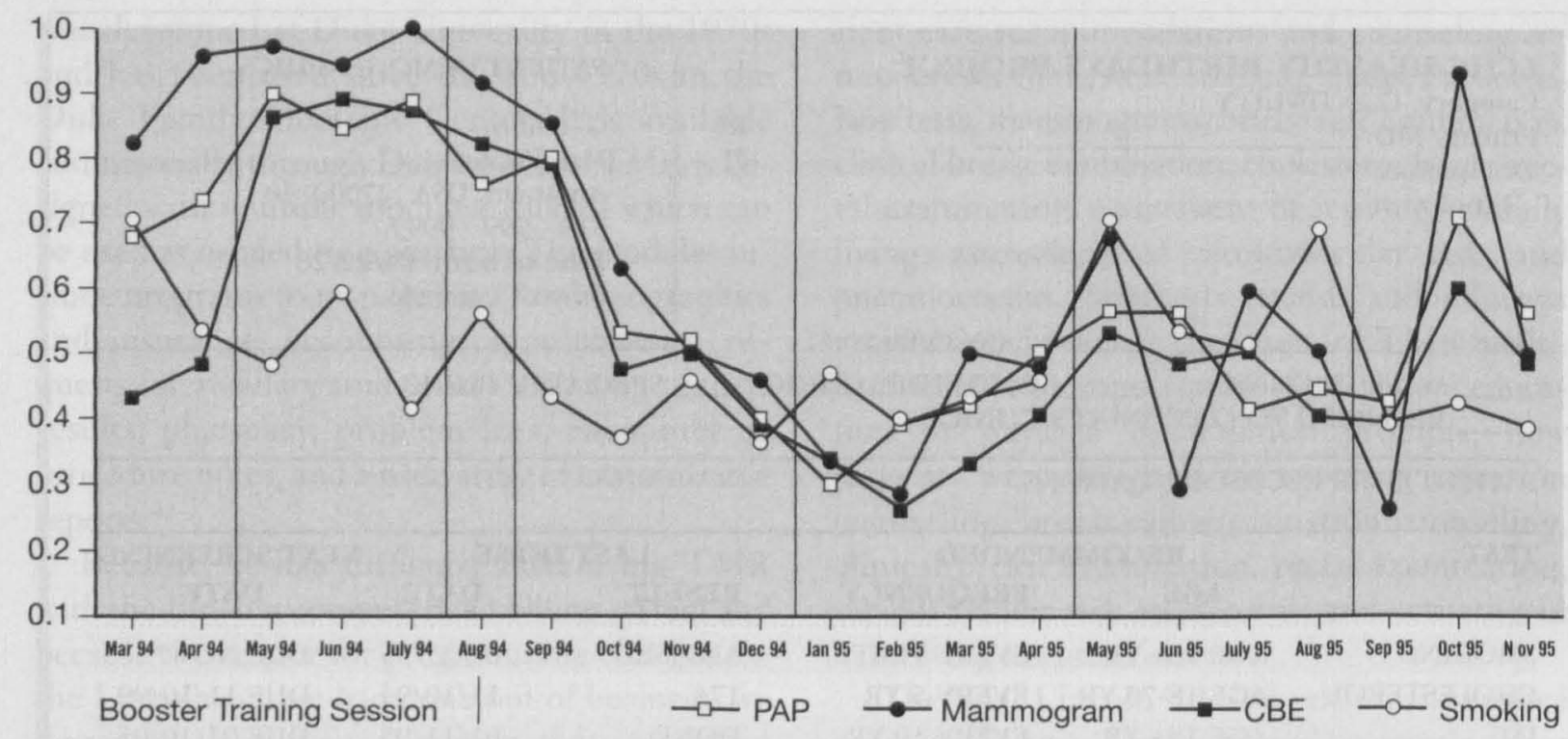

Figure 2. Monthly physician compliance with The Medical Record (TMR) computer form at Lincoln Community health Center for Papanicolaou (Pap) tests, mammography, clinician breast examination (CBE), and smokingcessation counseling.

The rationale for the detailed data collection on actual events of the encounter was to allow analysis of the various behaviors that occur in the office setting. To date, few if any studies have evaluated how frequently physicians use prompting systems or what portion of the system is rated most useful by physicians.

\section{Training Lincoln Staff to Use TMR}

In January 1994, shortly after the Lincoln TMR system became operational, clinicians, nurses, and the directors of Support Services and Medical Records at Lincoln attended an initial training session. Those attending learned how TMR operated and how its use could enhance clinicians' practices; they were also taught the ask-advise-assist-arrange follow-up model developed by the $\mathrm{NCI}^{41}$ to encourage clinicians to provide brief effective counseling on smoking cessation and cancer screening.

Individual training began at the initiation of TMR and continued throughout the study period. For example, as the clinical staff changed, newly hired clinicians received individual training before they began work. In addition, the data technician was available at Lincoln daily to provide support to clinicians.

Five approaches were used to keep the staff and clinicians' TMR skills up to date and to encourage full participation in the study:
1. A TMR manual was available in the physicians' work room.

2. Group refresher training sessions were offered initially in February and May of 1994 and quarterly for the first year, and were held whenever a new clinician was hired.

3. For the first 8 months and then quarterly, all staff received monthly newsletters or mailings listing changes in TMR and reinforcing providers for their use of TMR forms.

4. The study project manager raised awareness of the project among the staff at Lincoln by speaking about the status of the project during all routine meetings of the clinicians and staff.

5. The medical director at Lincoln received monthly statistical data on clinician compliance with TMR prompts.

\section{Results}

We assessed clinician compliance with using the TMR reminder forms and physician self-reported barriers to using the forms during a patient visit. Clinician compliance was defined specifically for the study as recording an action on the form for any screening test listed as deficient, regardless of what action the clinician took. This measure of compliance did not evaluate the percentage of completed screening tests; rather, it was a process measure that examined physician use of the prompting system. 


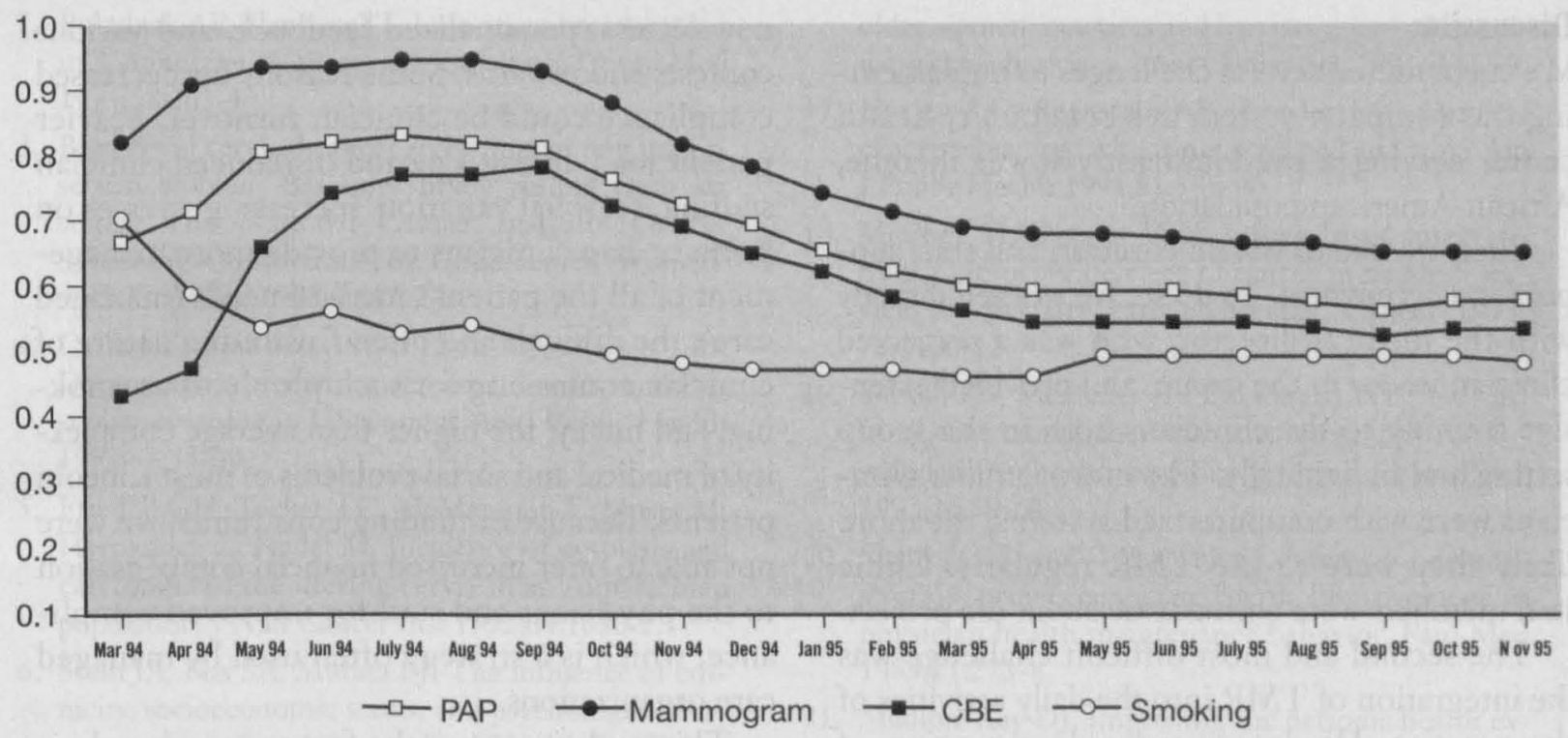

Figure 3. Cumulative physician compliance with The Medical Record (TMR) computer form at Lincoln Community Health Center for Papanicolaou (Pap) tests, mammography, clinician breast examination (CBE), and smoking-cessation counseling.

Initial clinician compliance rates in the first 5 months of the study for mammograms, Papanicolaou tests, clinician breast examinations, and smoking cessation counseling were 95 percent, 82 percent, 77 percent, and 53 percent, respectively (Figure 2). Compliance for all measures dropped during the next 5 to 7 months for all interventions and ranged from 26 to 47 percent. The periodic addition of pep talks and training sessions for the clinicians did not appear to affect clinician compliance. The cumulative total for each screening test leveled off around the 14th month of the study, with cumulative compliance rates of 65 percent, 57 percent, 53 percent, and 48 percent, respectively, for the 21 months of the study (Figure 3).

\section{Barriers Faced by Clinicians}

Clinicians were surveyed 18 months into the study to determine their barriers to using the TMR form at patient visits and to recommending needed screening tests and counseling. Five of 7 clinicians reported that they completed the TMR form "most of the time." Most clinicians believed it was a good reminder system. The major reasons for not completing the TMR form were not enough time and the need to use and complete paper maintenance forms. The paper forms were standard Lincoln forms used for both study and nonstudy patients. When completing the TMR forms, one half of the clinicians stated that they addressed every screening test or counseling session that was indicated as "due now."

Completing the TMR form took less than 5 minutes per patient. The amount of time required to counsel patients and to perform screening tests, however, was 10 to 14 minutes for one half the clinicians and more than 15 minutes for the other half. Time to provide smoking-cessation counseling for new patients ranged from less than $5 \mathrm{~min}$ utes ( 4 of 7 clinicians) to 10 minutes or more ( 2 of 7 clinicians). Counseling for smoking cessation became less time-consuming for most clinicians during subsequent visits.

\section{Cost of Implementing TMR at Lincoln}

Evaluation of the costs of implementing the TMR computerized reminder system is an important aspect of our larger study. Start-up costs included personnel time for design, setup, and training activities; consultant costs; equipment purchase and installation; resources; and supplies. Start-up costs for the 1318 study patients at Lincoln were $\$ 23,332.08$ in 1992 dollars (\$17.70 per patient). Had the system been used for the entire Lincoln patient population, the initial start-up costs would not have increased; instead, the number of anticipated patients would have been 10,183 , resulting in per patient start-up costs of \$2.29. Maintenance costs, not calculated for this analysis, will be reported at a later date. 


\section{Discussion}

We encountered several challenges to implementing this computer system in a community health center serving a predominantly lower income, African-American population.

First, we had to obtain clinician and staff support and acceptance. To do so, we worked directly with the medical director, who was a respected clinician leader in the group, and provided extensive training to the clinicians both in the group setting and individually. The more familiar clinicians were with computerized systems, the more likely they were to use TMR regularly. Clinic staff members were enthusiastic about the project.

The second and most difficult challenge was the integration of TMR into the daily activities of the practice. We integrated only a portion of TMR into the practice, which maintained its paper chart as the master copy of all the patient records and its own billing and scheduling computer system. Our inability to link the Lincoln computer system with TMR resulted in a less efficient computerized prompting system with builtin barriers, specifically, the need to complete an additional health maintenance form.

Our study highlights some of the difficulties encountered when two divergent computer systems are interfaced. Our experience with interfacing other clinical computer systems has shown that it is a difficult task at best; in this case, it was not possible. This system might not be generalizable to practices having the resources to purchase and install complete office computer systems that handle appointments, accounting, laboratory and $x$-ray test ordering and results, and clinical medical records. Our experience, however, is probably similar to other community health center and public health settings where funds and resources are more limited.

As part of the initial evaluation of TMR, we tracked the compliance levels of clinicians in completing the prompting forms. Although initial clinician compliance levels hovered around 95 percent for mammography, they were only 53 percent for smoking cessation. Compliance levels decreased measurably during the next 7 months and then rose to a steady state of 40 to 50 percent compliance with any given counseling or screening test. This drop in compliance occurred despite multiple group and one-on-one training sessions with clinicians and staff or reminder letters, newsletters, personalized feedback, and various contests and rewards. Some reasons for decreased compliance could be clinician turnover, heavier patient load during a period of reduced clinician staffing, seasonal variation, increasing stresses on primary care clinicians to provide more management of all the patient's medical needs (managed care), the difficult and often frustrating nature of clinician counseling for such problems as smoking, and finally, the higher than average complexity of medical and social problems of most Lincoln patients. Because of funding constraints, we were not able to offer increased financial compensation to the physicians and staff for improved compliance, which is a strategy often used by managed care organizations.

This study is among the first to examine clinician use of a prompting system in a community health setting. Our data suggest that even with state of-the-art prompting devices, clinicians used the prompts only 50 percent of the time and completed needed health maintenance in less than 50 percent of the office visits. Our study findings suggest that a major barrier to physicians' performing screening is lack of time during the encounter, which is not surprising, as most primary care physicians must address both the patients' agendas and presenting complaints and screening in an average 10 - to 15 -minute visit. Thus, if patients are to get the screening tests needed to meet the goal of Healthy People 2000, additional intervention methods, such as tailored, personalized written feedback and telephone counseling, which can be adjuncts to the clinician, will be vital.

In summary, we found that a computerized prompting system can be implemented and used in a community health center, but its effectiveness was limited by the costs of interfacing to the preexisting, often archaic, computerized billing systems. Use of the computerized prompting system by community health center physicians was constrained by a number of factors, including lack of physician time during the encounter. Counseling was undoubtedly increased as a consequence of prompting, but other system changes and patient interventions will be required to achieve a greater impact.

\section{References}

1. Freeman HP. Cancer in the socioeconomically disadvantaged. CA Cancer J Clin 1989;39:266-88. 
2. Polednak AP, Flannery JT. Late-stage breast cancer in Connecticut's three largest cities. Conn Med 1994;58:261-4.

3. Breast and cervical cancer screening among underserved women. Baseline survey results from six states. The National Cancer Institute Cancer Screening Consortium for Underserved Women. Arch Fam Med 1995;4:617-24.

4. Calle EE, Flanders WD, Thun MJ, Martin LM. Demographic predictors of mammography and Pap smear screening in US women. Am J Public Health 1993;83:53-60.

5. Friedell GH, Tucker TC, McManmon E, Moser M, Hernandez C, Nadel M. Incidence of dysplasia and carcinoma of the uterine cervix in an Appalachian population. J Natl Cancer Inst 1992;84:1030-2.

6. Stein JA, Fox SA, Murata PJ. The influence of ethnicity, socioeconomic status, and psychological barriers on use of mammography. J Health Soc Behav 1991;32:101-13.

7. Lane DS, Polednak AP, Burg MA. Breast cancer screening practices among users of county-funded health centers vs women in the entire community. Am J Public Health 1992;82:199-203.

8. Costa MJ, Grimes C, Tackett E, Naib ZM. Cervicovaginal cytology in an indigent population. Comparison of results for 1964, 1981, and 1989. Acta Cytol 1991;35:51-6.

9. Vogel VG. Early detection, epidemiology, and prevention of breast cancer. Cur Opin Oncol 1992;4; 1017-26.

10. Cigarette smoking among adults - United States, 1993. MMWR Morbid Mortal Wkly Rep 1994;43: 925-30.

11. Zapka JG, Chasan L, Barth R. Mas E, Costanza ME. Emphasizing screening activities in a community health center: a case study of a breast cancer screening project. J Ambul Care Manage 1992;15:38-47.

12. Lacey L, Whitfield J, DeWhite W, Ansell D, Whitman $S$, Chen E, et al. Referral adherence in an inner city breast and cervical cancer screening program. Cancer 1993;72:950-5.

13. Screening mammography: A missed clinical opportunity? Results of the NCI Breast Cancer Screening Consortium and National Health Interview Survey Studies. JAMA 1990;264:54-8.

14. Grady KE, Lemkau JP, McVay JM, Reisine ST. The importance of physician encouragement in breast cancer screening of older women. Prev Med 1992; 21:766-80.

15. Rimer BK, Trock B, Balshem A, Engstrom PF, Rosan J, Lerman C. Breast screening practices among primary physicians: reality and potential. $\mathrm{J}$ Am Board Fam Pract 1990;3:26-34.

16. Weinberger M, Saunders AF, Samsa GP, Bearon LB, Gold DT, Brown JT, et al. Breast cancer screening in older women: practices and barriers reported by primary care physicians. J Am Geriatr Soc 1991;39:22-9.

17. Harlan LC, Bernstein AB, Kessler LG. Cervical cancer screening: who is not screened and why? Am J Public Health 1991;81:885-90.

18. McPhee SJ, Detmer WM. Office-based interventions to improve delivery of cancer prevention services by primary care physicians. Cancer 1993; 72:1100-12.

19. Yarnall KS, Michener JL, Broadhead WE, Tse CK. Increasing compliance with mammography recommendations: health assessment forms. J Fam Pract 1993;36:59-64.

20. Shank JC, Powell T, Llewelyn J. A five-year demonstration project associated with improvement in physician health maintenance behavior. Fam Med 1989;21:273-8.

21. Madlon-Kay DJ. Improving the periodic health examination: use of a screening flow chart for patients and physicians. J Fam Pract 1987;25:470-3.

22. Mandel IG, Franks P, Dickinson JC. Screening guidelines in a family medicine program: a five-year experience. J Fam Pract 1982;14:901-7.

23. Wayland MT, Culik D, Goldsby C, Carion W, Orzame $\mathrm{N}$. Screening by family practice and internal medicine residents and the effect of an intervention program. J Med Educ 1987;62:519-22.

24. Cohen DI, Littenberg B, Wetzel C, Neuhauser D. Improving physician compliance with preventative medicine guidelines. Med Care 1982;20:1040-5.

25. Turner BJ, Day SC, Borenstein B. A controlled trial to improve delivery of preventive care: physician or patient reminders? J Gen Intern Med 1989;4:403-9.

26. McDonald CJ, Hui SL, Smith DM, Tierney WM, Cohen SJ, Weinberger M, et al. Reminders to physicians from an introspective computer medical records. A two-year randomized trial. Ann Intern Med 1984;100:130-8.

27. McDonald CJ. Protocol-based computer reminders, the quality of care and the non-perfectability [sic] of man. N Engl J Med 1976;295:1351-5.

28. Tierney WM, Hui SL, McDonald CJ. Delayed feedback of physician performance versus immediate reminders to perform preventive care. Effects on physician compliance. Med Care 1986;24:659-66.

29. Becker DM, Gomez EB, Kaiser DL, Yoshihasi A, Hodge RH Jr. Improving preventive care at a medical clinic: how can the patient help? Am J Prev Med 1989;5:353-9.

30. Schreiner DT, Petrusa ER, Rettie CS, Kluge RM.

- Improving compliance with preventive medicine procedures in a house staff training program. South Med J 1988;81:1553-7.

31. Davidson RA, Fletcher SW, Retchin S. Duh S. A nurse-initiated reminder system for the periodic health examination: implementation and evaluation. 
Arch Intern Med 1984;144:2167-70.

32. Fordham D, McPhee SJ, Bird JA. Rodnick JE, Detmer WM. The cancer prevention reminder system. MD Comput 1990;7:289-95.

33. Ornstein SM, Garr DR, Jenkins RG, Rust PF, Arnon A. Computer-generated physician and patient reminders. Tools to improve population adherence to selected preventive services. J Fam Pract 1991;32:8290.

34. Chambers CV, Balaban DJ, Carlson BL, Ungemack JA, Grasberger DM. Microcomputer-generated reminders. Improving the compliance of primary care physicians with mammography screening guidelines. J Fam Pract 1989;29:273-80.

35. Hatwick MA, Hart RJ. Medical exegesis: getting the most out of computer-based information systems. In: Blum BI, editor. Proceedings of the Sixth Annual Symposium on Computer Applications in Medical Care. New York: IEEE, 1982:72-174.

36. McPhee SJ, Bird JA, Jenkins CN, Fordham D. Promoting cancer screening. A randomized controlled trial of three interventions. Arch Intern Med 1989;149:1866-72.

37. Haug PJ, Gardner RM, Tate KE, Evans RS, East $T D$, Kuperman G, et al. Decision support in medi- cine: examples from the HELP system. Comput Biomed Res 1994;27:396-418.

38. Turner BJ, Amsel Z, Lustbader E, Schwartz JS, Balshem A, Grisso JA. Breast cancer screening: effect of physician specialty, practice setting, year of medical school graduation, and sex. Am J Prev Med 1992;8(2):78-85.

39. McDowell I, Newell C, Rosser W. Computerized reminders to encourage cervical screening in family practice. J Fam Pract 1989;28:420-4.

40. Chodroff $\mathrm{CH}$. Cancer screening and immunization quality assurance using a personal computer. QRB Qual Rev Bull 1990;16:279-87.

41. Manley M, Epps RP, Husten C, Glynn T, Shopland D. Clinical interventions in tobacco control. A National Cancer Institute training program for physicians. JAMA 1991;266:3172-3.

42. Yarnall KS, Michener JL, Hammond WE. The medical record: a comprehensive computer system for the family physician. J Am Board Fam Pract 1994;7:324-34.

43. King ES, Rimer BK, Seay J, Balshem A, Engstrom PF. Promoting mammography use through progressive interventions: is it effective? Am J Public Health 1994;84:104-6. 